\title{
Ectopic intra-aortic insertion of a subclavian central venous catheter: Case report and review of the literature
}

\author{
Mohamed I. Seleem, FRCS, MD, FACS, FICS, Ahmed M. Al-Hashemy, FACHARTZ, and \\ Awaje Al-Naemi, MBBS, Khamis Mushayt, Kingdom of Saudi Arabia
}

\begin{abstract}
Clinical Summary
A 70-year-old Saudi female patient with a known case of end-stage renal disease had been receiving regular hemodialysis for the last 6 years. She underwent left subclavian venous catheter insertion as a temporary form of access. During dialysis through the catheter, the attending nurse observed a very good flow to the machine but high resistance back to the circulation. An ectopic intra-arterial insertion of the catheter was suspected. Angiography through the catheter showed the tip of the catheter inside the aortic arch (Figure 1). Computed tomographic scanning confirmed the intraaortic position of the catheter, with the point of entry at the root of the left common carotid artery (Figure 2). The patient underwent median sternotomy, removal of the catheter from the aortic arch, and closure of the entry site with a 2-0 Prolene suture (Ethicon, Inc, Somerville, NJ). The patient did well after the operation, the chest tube was removed on the third postoperative day, and the patient was discharged home after 10 days without complication.
\end{abstract}

\section{Discussion}

Subclavian catheterization was first described by Aubaiac in 1952. ${ }^{1}$ In 1962, Wilson and associates ${ }^{2}$ used subclavian catheterization as a method of monitoring central venous pressure. In 1967, Shapira and Stern ${ }^{3}$ described 2 patients who died of massive pneumothorax after subclavian catheterization and recommended that the subclavicular technique should abandoned. The complication rates of infraclavicular subclavian vein catheterization vary in different studies. Borja ${ }^{4}$ reported a complication rate of $0.4 \%$ to 9.9\% attributable to the procedure. In a comparative study between the infraclavicular and supraclavicular approaches, the major complication was cited in $6 \%$ and $1.2 \%$ of cases, respectively. ${ }^{5}$ The most common complication of subclavian vein catheterization is pneumothorax and subcutaneous emphysema, which account for $30 \%$ of all complications, ${ }^{6}$ followed by malposition at $29 \%$. $^{7}$ Subclavian artery puncture is the third most common, constituting

\footnotetext{
From the Department of Surgery, Armed Forces Hospitals, Southern Region, Khamis Mushayt, Kingdom of Saudi Arabia.

Received for publication Oct 24, 2003; accepted for publication Nov 3, 2003.

Address for reprints: Mohamed Ismail Seleem, FRCS, MD, FACS, FICS, Department of Surgery, Armed Forces Hospitals, Southern Region, PO Box 101, Khamis Mushayt, Kingdom of Saudi Arabia (E-mail: Saleem_1961@ hotmail.com).

J Thorac Cardiovasc Surg 2004;127:1515-6

$0022-5223 / \$ 30.00$

Copyright $\odot 2004$ by The American Association for Thoracic Surgery

doi:10.1016/j.jtcvs.2003.11.021
}

$20 \%$ of complications. ${ }^{6}$ Two cases of nonhemorrhagic cerebral infarction in the carotid and vertebrobasilar distributions immediately after inadvertent subclavian

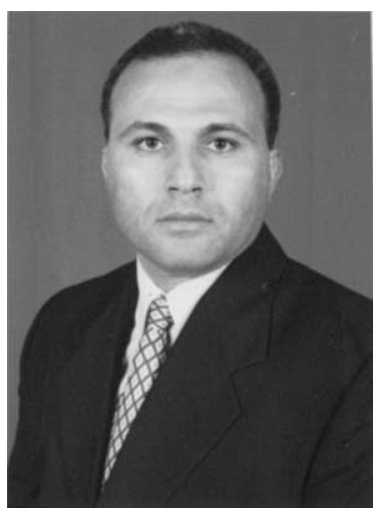

Dr M. I. Seleem artery puncture were reported. ${ }^{8}$ Coiled or knotted intravascular catheters could lead to catheter breakage and embolization. ${ }^{9}$ These catheters should be repositioned because they are more likely to traumatize the vein, resulting in perforation or thrombosis. ${ }^{10}$ The major error in the insertion technique that leads to catheter embolism is an attempt to withdraw the catheter through the sharply beveled needle. Because catheter embolization to the heart might lead to infection, thrombus formation, and myocardial perforation, removal of the embolized fragment is recommended and might require thoracotomy. ${ }^{11,12}$ Laceration of the internal thoracic artery has been reported from an attempted subclavian vein catheterization when sternotomy was required to control bleeding. ${ }^{13}$ Also, laceration of the carotid artery has been seen from a subclavicular approach, with hematoma formation that required hematoma evacuation. ${ }^{14}$ Holt and coworkers ${ }^{15}$ reported a case in which an apical branch of the pulmonary artery was lacerated, requiring thoracotomy for control of bleeding. Aortic catheterization from left subclavian artery catheter insertion is widely known, but direct puncture of the arch of the aorta during subclavian vein catheterization has not been reported before. We report our case to be the first in the literature. Vascular injury might result in a local extrapleural

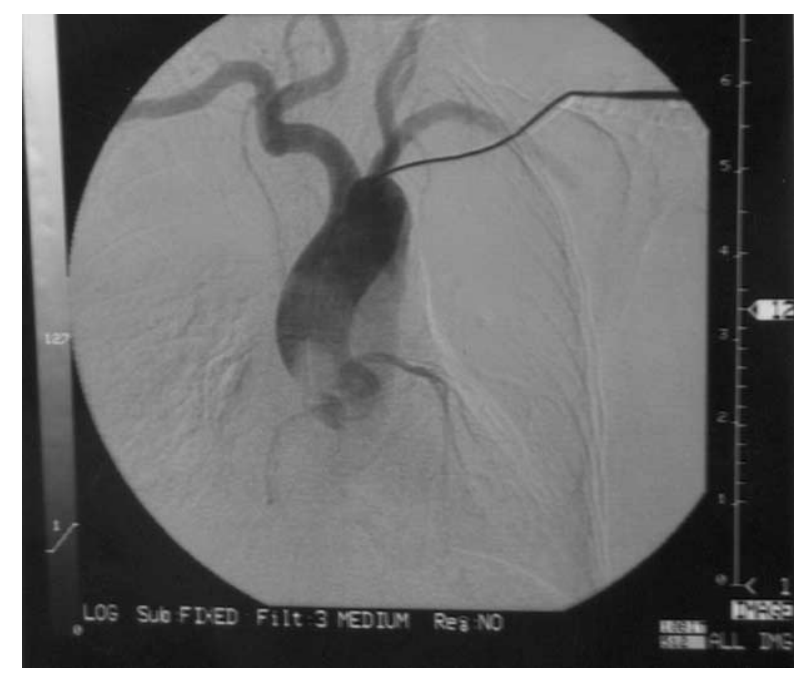

Figure 1. Angiogram through the subclavian catheter showed the tip of the catheter inserted directly into the arch of the aorta. 


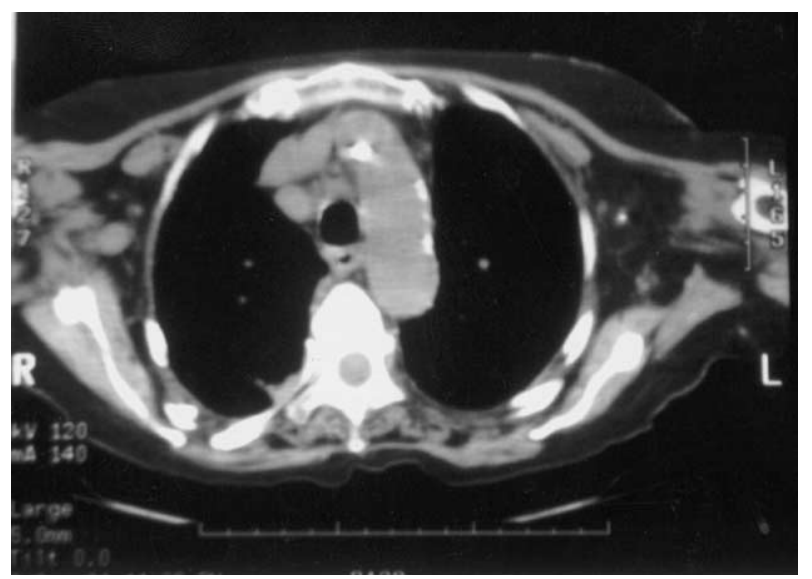

Figure 2. Computed tomographic scanning confirmed the position of the catheter in the arch of the aorta.

hematoma or might result in a large amount of blood loss into the chest. Usually this vascular injury is noticed immediately, responding to prompt withdrawal of the needle and local pressure. In our case the problem was detected after insertion of a 14-gauge catheter into the calcified arch of the aorta. Because of the fact that the aortic arch is not accessible for external compression, we were concerned about the possible formation of an aortic pseudoanurysm after removal of the catheter. For this reason, we preferred to explore the arch of the aorta through a median sternotomy and to control the hole after catheter removal under direct vision.

\section{Conclusion}

Our case presentation is the first to be published as a complication of subclavian vein catheterization. We presented this case as a rare case from the complication point of view and from the point of view of diagnosis and management.

\section{References}

1. Aubaiac R. L'injection intraveineuse sons-claviculaire. Presse Med. 1952;60:1456

2. Wilson JN, Grow JB, Demong CV, Prevedel AE, Owens JC. Central venous pressure in optimal blood volume maintenance. Arch Surg. 1962;85:563-78.

3. Shapira M, Stern WZ. Hazards of subclavian vein cannulation for central venous pressure monitoring. JAMA. 1967;201:327-9.

4. Borja AR. Current status of infraclavicular subclavian vein catheterization. Ann Thorac Surg. 1972;13:615-24.

5. James PM, Myers RT. Central venous pressure monitoring; complications and a new technique. Am Surg. 1973;39:75-81.

6. Smith BE, Modell JH, Gaub ML, Moya F. Complications of subclavian vein catheterization. Arch Surg. 1965;90:228-9.

7. Deitel M, Mclntyre JA. Radiographic confirmation of the site of central venous pressure catheters. Can J Surg. 1971;14:42-52.

8. Hurwitz BJ, Posner JB. Cerebral infarction complicating sub-clavian vein catheterization. Ann Neurol. 1977;1:253-64.

9. Nicolas F, Fenig J, Riditer RM. Knotting of subclavian central venous catheter [letter]. JAMA. 1970;214:373-4.

10. Johnson CL, Lazarchick J, Lynn HB. Subclavian venipuncture; preventable complications; report of two cases. Mayo Clin Proc. 1970; 45:712-9.

11. Doering RB, Stemmer EA, Connolly JE. Complications of in-dwelling venous catheters, with particular reference to catheter embolus. Am J Surg. 1967;114:259-66.

12. Fenn JE, Stansel HC. Certain hazards of the central venous catheter. Angiology. 1969;20:38-43.

13. Larsen HW, Lindahl F. Lesion of the internal mammarian artery caused by infraclavicular percutaneous catheterization of the subclavian vein. Acta Chir Scand. 1973;139:571-2.

14. Ryan JA, Abel RM, Abbott WM, Hopkins CL, Chesney TM, Colley R, et al. Catheter complications in total parenteral nutrition. $N$ Engl J Med. 1974;290:757-61.

15. Holt S, Kirkham N, Myerscough E. Hemothorax after subclavian vein cannulation. Thorax. 1977;32:101-3. 